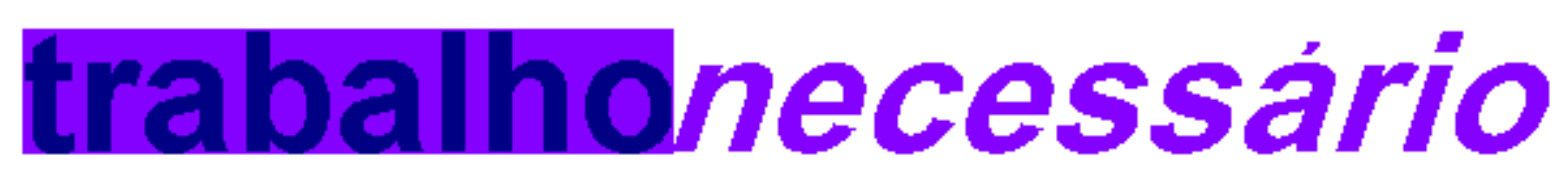

issn: $1808-799 \mathrm{X}$

ano 5 - número 5 - 2007

ENSAIO

\title{
PARA NÃO DIZER QUE NÃO FALEI DE MITOS A CAMPANHA PUBLICITÁRIA DO PROUNI
}

Bruno Fernando de Castro[i]

\section{A PROPAGANDA DO PROUNI (2005)}

O objeto de análise neste trabalho é será a propaganda áudio-visual do Programa Universidade Para Todos (ProUni), do Governo Federal, produzida pela agência Lew Lara Propaganda e Comunicação LTDA[ii]. Esta foi ao ar a partir do dia 17 de novembro de 2005. Exibida frequentemente durante o horário nobre televisivo. Verificou-se que a veiculação se deu basicamente em duas emissoras: TVE (canal televisivo estatal) e Rede Globo (maior conglomerado brasileiro de comunicação). Só lembrando que o governo é o maior responsável pelo orçamento publicitário das grandes empresas de comunicação no país.

A propaganda consiste, basicamente, em um rapaz cantando uma música da MPB dos anos 1960 acompanhado por um coro feminino. Este rapaz segue "caminhando e cantando", e a ele se juntam outros jovens que o acompanha até o fim do vídeo. O passeio termina quando eles chegam a um prédio sem indicação do que seja. Ao que entra uma 
voz em off:

O ProUni, Programa Universidade Para Todos, do Governo Federal, já colocou mais de 100 mil jovens na faculdade.

O ProUni oferece bolsas gratuitas ou com $50 \%$ de desconto em faculdades particulares de todo o Brasil.

Faça parte dessa revolução na educação brasileira.

Ministério da Educação. Brasil, Um País de Todos.

O comercial mostra então o jovem cantor utilizando um computador e uma mensagem textual sobreposta à imagem com os contatos para o cadastro no programa, finalizando com a logomarca do atual governo federal.

A música cantada é Para não dizer que não falei das flores, da autoria de Geraldo Vandré, composta no ano de 1968. Tornou-se um dos principais hinos de resistência e luta contra a Ditadura Civil-Militar que se instaurou no Brasil a partir de um golpe de estado em 1964, e que perdurou até 1985.

Caminhando e cantando e seguindo a canção

Somos todos iguais, braços dados ou não

Nas escolas, nas ruas, campos, construções

Caminhando e cantando e seguindo a canção

Vem, vamos embora que esperar não é saber

Quem sabe faz a hora, não espera acontecer

Na propaganda, a música é interpretada "caminhando e cantando" por um jovem negro, seu desempenho é acompanhado por um trio de jovens negras. O novo arranjo dado à música, acrescido da performance dos intérpretes, faz-nos lembrar a Black Music americana além de Hair, filme cult do final da década de 1970.

No início do vídeo mostra o jovem cantor negro sentado segurando a bandeira do Brasil. Quando a melodia se inicia, o arranjo introdutório é puxado pelo coro de três jovens negras. A cena é cortada para um jogo de street basket, o qual mostra uma disputa pela bola entre um branco e um negro, com este tendo a posse da mesma. Retoma-se a cena que apresenta o coro feminino, e, logo em seguida, o cenário é novamente o jogo de street basket. A bola ainda está com 0 jogador negro. O jovem cantor atravessa o jogo "caminhando e cantando" com um semblante sério. Há uma sincronia invertida nesta cena, quando canta "caminhando", o foco está na boca do intérprete, e a letra diz "cantando", o foco passa para os seus pés. Nesta cena em que os pés do cantor são focalizados, a 
câmera se afasta e o mostra atravessando uma passagem subterrânea. Alguns outros jovens passam a segui-lo, notadamente um cadeirante.

A próxima cena apresenta o intérprete passando pelas jovens do coro. Ele está então em uma espécie de área pavimentada ao ar livre cercada de prédios. Quando o cantor atravessa uma espécie de passarela, um jovem branco com uniforme da seleção brasileira de futebol se levanta e o segue. Na seqüência, o cantor é apresentado com um número maior de "seguidores".

Prosseguindo o vídeo, a câmera passa a enfocar o grupo de jovens caminhando numa calçada a partir da calçada do outro lado da rua. Nesta cena temos um idoso dando corda numa aparente caixinha de música, um realejo. Ainda nesta cena, temos dois carros estacionados, do lado dos jovens uma Variant, e do lado do senhor um Fusca, ambos carros comuns na década de 60.

Desta vez, o comercial mostra um número ainda maior de "caminhantes", após atravessarem outra espécie de passarela. Há um close em alguns dos jovens que acompanham o cantor, em meio a esses zooms há um outro close nos ante-braços do intérprete, erguidos e com os punhos cerrados demonstrando firmeza, símbolo dos movimentos sociais étnicos estadunidenses dos anos 1960, como os Panteras Negras. Após mais uma performance do coro, entra a voz em off falando sobre o ProUni. Daí então, a cena apresenta este grupo entrando no que seria uma faculdade. A câmera, que não abandona o cantor por mais de 3 segundos, o focaliza, dessa vez, com uma expressão fácil mais suave, esboçando um sorriso. Depois deste, o cantor, que já encerrou sua atuação musical desde a entrada da voz em off, manuseia um computador. A esta cena se sobrepõe uma imagem textual com o contato para se cadastrar no programa. A propaganda encerra com a inscrição do Ministério da Educação e a logomarca do Governo Federal, sobrepostos a cena de um corredor dentro de uma edificação cheia de jovens, conversando e levando livros nas mãos, podendo, assim, ser interpretada como uma faculdade.

\section{FUNDAMENTAÇÃO TEÓRICA: ANÁLISE CRÍTICA DO DISCURSO}

Para a análise deste material publicitário, nos valemos da análise do discurso orientada, basicamente, pelos pressupostos de Mikhail Bakhtin (1992) e Norman Fairclough (2001). Este propõe a análise do discurso a partir de um modelo tridimensional, afirmando que toda formação discursiva cria uma cadeia, onde se forma uma série com os outros discursos. Ambos concordam que não devemos nos reter apenas à análise textual do objeto, e sim atentarmos aos condicionantes históricos e contextuais, tais como os lugares de fala, que estão dialogando e sendo disputados. Por isso o conceito bakhtiniano de intertextualidade e dialogia[iii] formam uma ferramenta privilegiada para a análise todo 
signo, que é sempre ideológico como afirma o autor russo. Donde ele conclui que o discurso é sempre diacrônico, sempre se relaciona com o passado, presente e futuro. E para a narrativa entrar na ordem do discurso, tal qual definida por Michel Foucault (2004), ele deverá qualificar-se, cumprindo certas exigências, como dialogar com discursos já consolidados, por isso o fato de utilizarem uma música dos anos 1960, pois há uma sensação saudosista compartilhada na memória social de que aqueles eram anos de maior engajamento e militância juvenil. Apesar de tomar o conceito de formação discursiva de Foucault, Fairclough conclui afirmando que, para uma segura e contundente análise do discurso, devemos situá-lo dentro do contexto sócio-histórico em que apareçam os sujeitos históricos socialmente posicionados, o que parece inexistir em algumas obras de Foucault, segundo a principais críticas à obra do autor francês. Porém, a método como Fairclough se apropria deste conceito, se assemelha bastante ao que Bourdieu conceituou como campo [iv]. Estas seriam as duas primeiras etapas do modelo tridimensional de análise discursiva proposto por Fairclough, por isso restando apenas a última. No terceiro momento da análise, propõe ele, devemos nos voltar para o contexto histórico atual ao objeto estudado, procurando não apenas apreciá-lo criticamente, mas também relacionando o aspecto textual e intertextual observado no objeto. E a partir de uma visão mais totalizante, atentarmos às disputas pela hegemonia no contexto social estudado, tomando como base as argutas análises de Antonio Gramsci[v].

\section{A CAMPANHA PUBLICITÁRIA DO PROUNI (2005)}

O início da propaganda mostra o jovem cantor negro segurando a bandeira do Brasil, depois um jogo de street basket, o qual o cantor atravessa. Momentos depois, o cantor é seguido por outro jovem com a camisa da seleção brasileira de futebol. Podemos perceber a polifonia, tal qual proposta por Mikhail Bakhitin, de, a princípio, dois contextos que dialogam entre si: o brasileiro - marcado pela bandeira, pela música cantada em português e pelo rapaz com a camisa da seleção brasileira de futebol - e o norte-americano marcado pelo estilo musical e pelo jogo de street basket. Neste caso, a intertextualidade, outro conceito tomado a partir da obra bakhitiniana, apresenta-se no diálogo do aspecto norte-americano, com seu poder de influência devido a sua hegemonia sobre a esfera cultural-econômico-militar mundial. Estendendo-se a entidades econômicas mundiais como o Fundo Monetário Internacional (FMI) e o Banco Mundial - um dos maiores financiadores em educação no mundo, inclusive no Brasil, desde que cumpridas suas exigências na organização educacional do país[vi]. Como o ProUni é um programa que se propõe ampliar o acesso aos curso de graduação, a discursividade norte-americana é apresentada relacionalmente, na propaganda, como modelo/exemplo a ser seguido.

Há ainda o discurso neoliberal, modelo econômico da maioria das potências mundiais, onde os Estados Unidos apresentam-se como a maior, a hegemônica. Uma das premissas do neoliberalismo é a diminuição da atuação do Estado na sociedade, ele seria apenas 
uma espécie de agência reguladora e mediadora entre a sociedade e a ordem política econômica mundial. Ao definir os setores que compõe o Estado, essa ideologia designou Setores de Serviços não exclusivos do Estado e nele colocou a educação, a saúde e a cultura[vii]. O ProUni é um exemplo dessa ideologia, pois, ao invés de investir no ensino superior público, o governo compra as vagas ociosas das faculdades particulares. A projeção desta definição é ainda mais assombrosa, pois a educação deixa de ser concebida como um direito e passa a ser considerada um serviço, e ainda deixa de ser considerada um serviço público passando a ser considerada um serviço que pode ser privado ou privatizado. Ademais, a reforma do Estado definiu a universidade como uma organização social e não mais como uma instituição social.[viii] A grande ironia é que enquanto a assistência às universidades públicas deixa de ser uma prioridade, concede ajudas e financiamentos às particulares a partir de programas como o Programa de Financiamento Estudantil (FIES) e o ProUni, assim como através de privilégios fiscais e reduções tarifárias. Com essa forte inserção de entidades particulares no ensino, seja básico ou superior, e o progressivo abandono do Estado para com as entidades públicas de ensino, a lógica capitalista da concorrência insere-se no âmbito educacional transformando a educação em uma mercadoria, um artigo para a compra e venda, sendo a sua metodologia de ensino norteada pela necessidade do mercado de trabalho, associando a concorrência no campo da educação como mecanismo chave de qualidade. Esquece-se a formação do aluno, do cidadão, do desenvolvimento de um pensamento crítico da sociedade, afinal, a preocupação declarada é com a eficiência da educação e não com a formação de cidadãos criticamente ativos.

Verificamos uma medida afirmativa racial no fato de a musica ser interpretada apenas por negros. A insterdiscursividade étnica também está presente nas cenas do jogo de street basket. Nelas, a bola está sendo disputada por dois jovens, um branco e um negro, e a posse da bola está com o negro nas duas cenas. Este discurso estaria dialogando com o passado brasileiro, quando, na disputa pela bola, esta sempre esteve com os brancos. Neste contexto, portanto, é a vez do negro estar com a bola. Sem desconsiderarmos as disputas inerentes, que tanto pode servir para a segmentação racista da sociedade quando o que está em questão é a disputa e a ideologia multiculturalista -, quanto para afirmar o diálogo e as negociações entre os sujeitos - quando o que está em questão é o jogo. Em relação ao tema étnico, há uma inversão de valores historicamente construídos quando mostra o jovem negro sendo seguido pelo seu apelo imbricado na letra da música. Podemos concluir, então, que há, como foi demonstrado, perigos sutis ao abordarmos temas sociais e étnicos.

Esta preocupação com o papel dos negros na propaganda pode ser associada à questão das ações afirmativas. Um dos principais objetivos delas é a reserva de vagas (cotas) para negros, deficientes físicos e minorias étnicas, que o governo tenta implementar. Esta conclusão é reforçada pela presença de um cadeirante entre a marcha dos jovens. 
Portanto, esta interdiscursividade está dialogando com outros projetos de cunho social do governo. É o mote da inclusão social de segmentos da sociedade até então marginalizados, como é o caso dos portadores de necessidades especiais. Mas, ao não conseguir regular a questão da reserva de vagas para todo o ensino superior público, 0 governo chama os negros e cadeirantes para fazer parte "dessa revolução na educação brasileira", nesse caso possibilitada através da compra de vagas ociosas em faculdade particulares e as financiando para quem não conseguiu entrar numa pública.

A intertextualidade presente na escolha da música são muitas. A composição de Geraldo Vandré, como foi dito, foi um dos hinos da resistência e luta contra a Ditadura Civil-Militar em seu período mais severo - após o Ato Institucional no 5, em 1968. Como o discurso é sempre diacrônico, ele sempre se relaciona com o passado, presente e futuro, assim, essa música sendo interpretada enquanto um grupo de jovens caminham juntos, relaciona esse movimento a uma espécie de passeata, como as que havia no período da ditadura, reivindicando seus direitos, onde a atuação/participação dos jovens era significativa. Em contrapartida, os jovens na propaganda seguem o caminho traçado pelo cantor com certa apatia. Poderíamos concluir que os jovens não devem "esperar", devem continuar "caminhando e cantando" seguindo o chamariz do programa (que se assemelha ao Flautista de Hamelin, personagem dos contos de fadas que, ao tocar sua flauta, fazia com que os ratos o seguissem). O uso dessa canção, a propósito, é uma forma de entrar na ordem do discurso, pois dialogando com os outros discursos já consolidados, satisfazemse certas exigências e qualifica o seu discurso.

Outro dado significativo sobre a música é, novamente, o ano de sua composição: 1968. Ano da reforma implementada no sistema universitário brasileiro pelo governo militar, e foi a última desde então[ix], pelo menos do ponto de vista legal/formal. Atualmente, o maior projeto do governo federal para a educação superior é, sem dúvida, a Reforma Universitária. Esta suscita inúmeras discussões e desacordos. Um dos sinais dessa reforma é justamente o ProUni. Por isso, o governo diz em sua propaganda: vem vamos embora, que esperar não é saber. Devemos ir "embora" junto com o governo, pois esperar seria discutir os pontos que geram os desacordos, porém, como o governo se mostra intransigente, para ele "esperar não é saber". O uso da música para conotar a atitude do governo em relação aos jovens parece não ir além desse trecho dela, pois, em sua continuação, a relação entre os personagens da canção é notadamente mais dialética que a do governo com esses jovens: caminhando e cantando e seguindo a canção / Aprendendo e ensinando uma nova lição.

A cena mais ambígua, com certeza, é a que os jovens caminham de um lado da calçada e do outro há um velhinho com uma caixinha de realejo, que acostumamos a ver na televisão acompanhada de um macaquinho que dança conforme a música tocada. Nesta cena há, ainda, dois carros: um fusca e uma variant, carros comuns no contexto de criação 
da música. Ambígua, novamente, porque podemos fazer diversas análises dessa cena. Uma delas seria o reforço dessa relação com o passado, no qual dizem que os jovens eram mais engajados e mobilizados. O velhinho representaria então esse passado, separado do presente pela rua, que poderia simbolizar o tempo, demonstrando que mesmo no presente o passado não deixa de ser pertinente. Exemplar é o fato de um dos carros estar do lado da rua onde os jovens passam. O velhinho girando a manivela do realejo pode ser interpretado como um apelo a ouvirmos o passado, pois, mesmo separados pela tempo/rua, o passado está presente. O próprio esforço físico demonstrado ao rodar a manivela pode ser associado justamente a esse esforço de manter o passado presente.

Uma interpretação diversa ainda é possível. $\mathrm{O}$ ato de dar corda na caixinha de música, e o fato de o jovem acompanhar a melodia e ser seguido por diversos outros jovens, pode ser interpretado como o velhinho representando o passado, hoje no governo - pois muitos de seus componentes são dessa época -, "dando corda" para os jovens seguirem para a aceitação do ProUni, e, quiçá, para a aceitação da Reforma Universitária. Semelhante a essa, podemos fazer ainda uma terceira interpretação, dentre as inúmeras possíveis. Como essa caixinha de música se assemelha àquelas que os macaquinhos dançavam conforme sua música, poderíamos associar o velhinho ao governo - mesmo porque muitos que fazem dele vivenciaram o contexto da década de 1960 representado nesta cena, e hoje não seriam tão jovens assim -, o macaquinho a esses jovens e a música aos programas do governo. Por isso os jovens/macaquinhos cantariam/dançariam conforme os programas/músicas do governo/velhinho.

Pode ser algo que Freud chamaria de superinterpretação, porém o fato de nessa cena só ter dois carros e estes serem da época da música e de muitos integrantes do nosso governo de esquerda, não é uma mera casualidade. Todas essas possíveis interpretações foram feitas para aludir a uma constatação de extrema relevância, feita tanto por Foucault quanto por Bakhitin, de que todo discurso é político, nada é dito por acaso. Por isso, sem querer reivindicar uma posição esclarecida/iluminista da análise de discursos, o exercício da criatividade nessas interpretações tem o intuito de estimular a mesma atitude nos leitores. Todos nós fazemos interpretações, apropriações e representações do que recebemos, mas o intuito é que, a partir da maneira que foi feita a análise, possam os leitores realizar interpretações mais críticas e contextualizadas, procurando atentar ao que está em disputa nos materiais discursivos.

É interessante observar que esta propaganda foi ao ar (17/11/2005) durante uma greve das universidades federais de todo o Brasil, e que se tornou a mais longa da categoria ao terminar no dia 20 de dezembro de 2005. É perceptível a tendência ao esvaziamento da luta pela qualidade das universidades públicas quando o governo leva ao ar um comercial propagandeando um projeto de financiamento de vagas em faculdades particulares, onde 
a grande maioria deste segmento em luta é contra essa Reforma Universitária. Enquanto os grevistas não aceitavam as propostas do governo, e a negociação se acirrava, este põe no ar a propaganda do ProUni. Demonstrando, com essa atitude, uma preocupação com o amparo às faculdades particulares ao preencher suas vagas ociosas, e um desprezo às faculdades públicas, visto o estado precário em que se encontra todo o sistema de ensino público brasileiro, e não apenas o superior. A tendência comum é achar que o ensino público, apesar de sua qualidade indiscutível em inúmeras áreas, ocorre em condições precárias, com o "perigo" de inúmeras greves ao longo de sua trajetória acadêmica, correndo o risco de prejudicar e atrasar sua formação. Neste nosso governo de esquerda, aprovou-se a criação de novos cursos em faculdades particulares como nunca visto antes, principalmente se compararmos com o número de vagas criadas em faculdade públicas.

\section{REFERÊNCIAS BIBLIOGRÁFICAS}

ANDERSON, Perry. "Balanço do neoliberalismo". In: SADER, Emir e GENTILI, Pablo. Pós-neoliberalismo: as políticas sociais e o Estado democrático. Rio de Janeiro: Paz e Terra, 1995.

BAKHITIN, Mikhail. Marxismo e Filosofia da Linguagem. São Paulo: Hucitec, 1992. BOURDIEU, Pierre. Questões de Sociologia. Rio de Janeiro, Marco Zero, 1983. BRASIL. Ministério da Educação e Cultura (MEC). Governo Federal. Lei de Diretrizes e Bases da Educação (Lei 9.394/96).

CHAUÍ, Marilena. "Sociedade, Universidade e Estado: autonomia, dependência e compromisso social". In: Seminário: Universidade: Por que e como reformar? MEC/SESu: 6 e 7 de agosto 2003.

FAIRCLOUGH, Norman. Discurso e Mudança Social. Brasília: Editora UnB, 2001. FOUCAULT, Michel. A Ordem do Discurso. São Paulo: Edições Loyola, 2004. GRAMSCI, Antonio. Os Intelectuais. O Princípio Educativo. Jornalismo. Rio de Janeiro: Civilização Brasileira, 2000.

TORRES, Rosa Maria. "Melhorar a qualidade da educação básica? As estratégias do Banco Mundial". In: TOMASI, Lívia. O Banco Mundial e as Políticas Educacionais. São Paulo: Cortez Editora / Ação Educativa / PUC-SP, 1996.

[i] Licenciado em História (UERJ-FFP) e graduando em Estudos de Mídia (UFF) brunofernandocastro@yahoo.com.br

[ii] Veja a propaganda: http://www.youtube.com/watch?v=WRMUN IYWR8

[iii] Podemos citar pelo menos um exemplo do uso deste conceito a partir do objeto analisado, como o fato da música utilizada comercial ter sido lançada originalmente em 1968, ano da última Reforma Universitária no Brasil, e, coincidentemente, ano que foi decretado o Al-5 marcando o período de maior intolerância e intransigência do governo militar

[iv] Cf.: Bourdieu, 1983. 
[v] Para uma maior aproximação do conceito de hegemonia, conferir Gramsci, 2000.

[vi] Cf.: Torres, 1996.

[vii] Cf.: Anderson, 1995.

[viii] De acordo com o seminário apresentado pela Marilena Chauí sobre a Reforma Universitária (CHAUÍ, 2003), a distinção entre instituição social e organização social é de inspiração frankfurtiana, e é feita por Michel Freitag em Le naufrage de l'universite, Paris, Editions de la Découverte, 1996.

[ix] Pelo menos do ponto de vista legal/formal mais geral.

volta 